\title{
Progress overview of EUV resists status towards high-NA EUV lithography
}

\author{
Xiaolong Wang $^{\mathrm{a}^{*}}$, Li-Ting Tseng ${ }^{\mathrm{a}}$, Iacopo Mochi ${ }^{\mathrm{a}}$, Michaela Vockenhuber ${ }^{\mathrm{a}}$, Lidia van Lent-Protasova ${ }^{\mathrm{b}}$, Rolf \\ Custers $^{\mathrm{b}}$, Gijsbert Rispens ${ }^{\mathrm{b}}$, Rik Hoefnagels ${ }^{\mathrm{b}}$, Yasin Ekinci ${ }^{\mathrm{a}}$

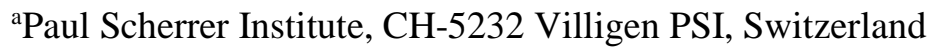 \\ bASML Netherlands B.V., De Run 6501, 5504 DR Veldhoven, The Netherlands
}

\begin{abstract}
We investigated how the processing parameters, including post exposure baking (PEB), and resist film thickness (FT) influence the dose and line width roughness (LWR) of different types of EUV resists, targeted for the high-NA EUV lithography. We compared the dose and LWR of molecular, inorganic and CAR resists at half-pitch (HP) of 16 and $14 \mathrm{~nm}$ for different PEB temperatures. The results show that without PEB or at lower PEB temperature, resists require higher doses, as expected. We also observed the different behavior of various resist platforms in response to variation of the film thickness. The results showed that there is a room for the optimization of the processing parameters to improve dose and LWR of molecular, inorganic and CAR resists for line/space printing at high resolution.
\end{abstract}

Keywords: Extreme ultraviolet lithography, EUVL, interference lithography, High-NA, Resist molecular/CAR/inorganic, dose-to-size, PEB

\section{INTRODUCTION}

In the last two decades EUV lithography (EUVL) has been developed to enable future progress in semiconductor manufacturing [1, 2], and this year it has entered into the high-volume manufacturing (HVM) phase at the $7 \mathrm{~nm}$ technology node [3, 4]. To enable future progress, high-NA EUVL is considered as the most viable option [5, 6]. To make sure that the HVM high-NA EUVL can be introduced to the market on time, EUV resists should be able to achieve the CD required at the $5 \mathrm{~nm}$ node and beyond with high sensitivity and low line edge roughness (LER). Therefore, further research and development is needed to find the best EUV resists with optimal resolution-LER-sensitivity (RLS) [7]. To achieve this goal, it is necessary to develop, evaluate, and understand the underlying mechanism of EUV resists before high-NA tools become available.

The EUV-IL tool at the XIL-II beamline of the Swiss Light Source (SLS) is a powerful and cost-effective tool to evaluate resist performance [2, 8-15]. One advantage of EUV-IL is that its theoretical resolution limit is HP $3.5 \mathrm{~nm}$ [16], which is much higher than the current and future EUV scanner with 0.33NA and 0.55NA [3]. The XIL-II tool has successfully achieved a world record of $6 \mathrm{~nm}$ HP [17] lines and has demonstrated single-digit resolution down to the $2.5 \mathrm{~nm}$ technology node [16]. With this tool we can investigate the LER/LWR, LCDU, and sensitivity of the EUV resist platforms at high resolutions and thereby contribute to the global efforts of EUV resist development.

In this work, we present how processing parameters like resist FT and PEB T can influence the performance of the stateof-art EUV resists for printing line/space of $16-14 \mathrm{~nm}$ HP. After the evaluation of $\sim 40$ resists, including molecular, inorganic and CAR resists, we compared the effects of FT and PEB on dose and LWR. We showed that PEB can strongly influence the dose without influencing the LWR significantly. It was found, that higher resist FT resulted in higher dose required to obtain the same $\mathrm{CD}$, for all three types of resist platforms. Also, with $10 \mathrm{~nm}$ thinner resist layer, the LWR can 
be decreased by half, for CAR resists. By investigation of the processing parameters, we show that there is still room for process optimization in order to print high-resolution line/spaces with reasonable dose and low LWR.

\section{EXPERIMENTAL METHODS}

The resist evaluation is performed by the interference lithography using the EUV-IL tool at the XIL-II beamline of SLS. The method and its working principle is schematically shown in Fig. 1. The transmission mask is illuminated perpendicularly with an EUV light with a polarization along the horizontal direction of the gratings. The diffracted beams from a grating pair (with a mutual angle of $\theta$ ) interfere on the surface of the photoresist-coated silicon wafer. We use the first-order diffracted beams for interference, and the relationship between the diffraction angle and the grating pitch is calculated as

$$
\sin (\theta / 2)=\lambda / P
$$

where $\theta / 2$ is the diffraction angle and $P$ is the period of the grating. The period $p$ of the resulting sinusoidal aerial image is a half of the period of the grating for the first-order diffraction

$$
p=\lambda / 2 \sin (\theta / 2)=P / 2
$$

With the wavelength $\lambda=13.5 \mathrm{~nm}$, the theoretical resolution limit of this EUV-IL is $3.5 \mathrm{~nm}$ [16].

The gap between the mask and the wafer surface varies depending on the pitch of the grating and is determined with the following equation:

$$
g=\frac{d}{2 \tan (\theta / 2)}
$$

where $g$ is the gap between the grating and the interference pattern (mask-wafer distance) and $d$ is the distance between the two gratings. We note that the depth-of-focus of the aerial image is infinite, which means that changing the gap does not affect the contrast of the image. Eq. 3 gives the optimal distance of mask-to-gap, for the maximum aerial image extension.

The aerial image can be line/space pattern, contact holes (CHs) or pillars pattern, or pattern with triangle lattice $[16,18]$. Figures 1(b) and (c) show two different grating configurations, two-beam and four-beam, that give line/space and $\mathrm{CHs} /$ pillars. The details of an effective double exposure theory for creating the CHs/pillar pattern with EUV-IL are described elsewhere [18]. In this work, we focus on two-beam interference that generates well-defined uniform contrast line/space. In a typical exposure, patterns with different half-pitches are simultaneously printed on the wafer. According of the principle of the technique (a.o. 'infinite' depth of focus), only through-dose exposures can be performed. Typical patterned areas are about $80 \times 80 \mu \mathrm{m}^{2}$ that is sufficient for the measurements. Large-area exposures of the fields up to $5 \times 5$ $\mathrm{mm}^{2}$ have been also demonstrated [19].

In the study, the exposed patterns were analyzed with SEM (Carl Zeiss SUPRA 55VP) at the acceleration voltage of $1 \mathrm{kV}$ and $7.5 \mu \mathrm{m}$ aperture. The CD values were calculated with a commercial software (SuMMIT ${ }^{\circledR}$ ), and the LWR values are estimated using $3 \sigma$ after filtering the high frequency noise with the unbiasing of the PSD curve [20]. 


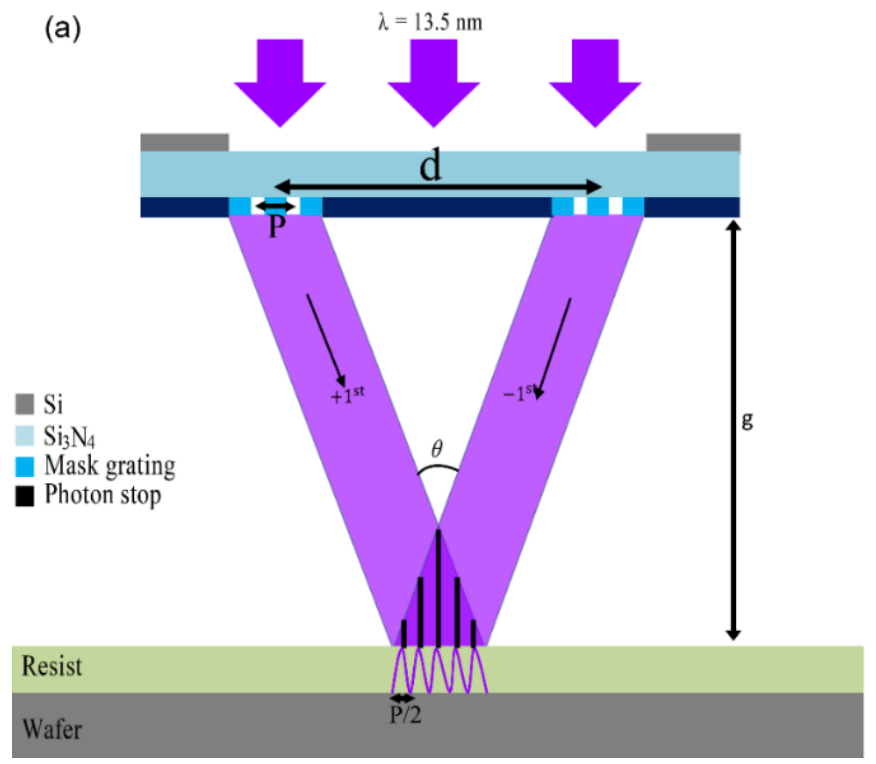

(b)

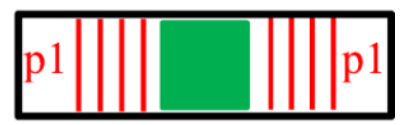

(c)

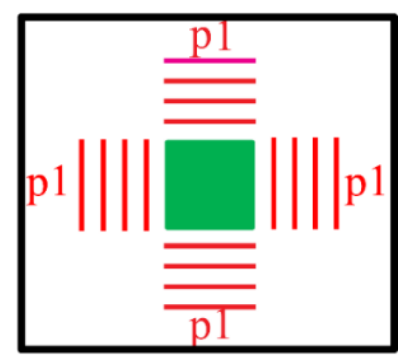

Figure 1. (a) EUV interference lithography principle. EUV light illuminates a transmission mask from the top. The mask consists of transmission diffraction gratings. The diffracted coherent beams form an interference pattern which is recorded in the photoresist. (b and c) Two- and four-beam interference gratings layout, respectively.

\section{RESULTS}

In this section, we first present the performance of the resists, including molecular, CAR and inorganic resists, from three resist vendors, which we have tested for printing line/spaces, using different PEB temperatures. We show how the PEB T influences the dose and the LWR, for three resists. Then we compare the dose and LWR of another three type molecular, inorganic and CAR resists with different resist FT at the same CD. We compare the critical parameters of the selected resist performance under different processing parameters for further optimization.

The SEM images of the 16 and 14nm LS of different resists are shown in Fig. 2. The dose dependences of CD and LWR for these resists are plotted in Fig. 3. The full comparison of the dose to size and LWR at different PEB temperatures for all three resists at different pitches are listed in Table 1. All three resists have resolved both HP 16 and $14 \mathrm{~nm}$. The dose dependency on the different PEB $\mathrm{T}$ is much more pronounced for molecular resist than for CAR and inorganic resist for both hp $16 \mathrm{~nm}$ and hp $14 \mathrm{~nm}$ as shown in Fig.3 (a)-(c) and Fig. 3 (j)-(l). For all the resists, the target CD is achieved at lower dose for higher PEB (blue curve compared to red curve). Particularly, the molecular resist A requires almost two times more dose to obtain the same CD for both hp $16 \mathrm{~nm}$ and $14 \mathrm{~nm}$ at PEB T when there is no PEB used. Dose-to-size was found to be $34.2 \mathrm{~mJ} / \mathrm{cm}^{2}$ with PEB, compared to the dose-to-size of $62.3 \mathrm{~mJ} / \mathrm{cm}^{2}$ without PEB (for hp $16 \mathrm{~nm}$ ). For hp14nm, dose of $38.3 \mathrm{~mJ} / \mathrm{cm}^{2}$ was needed with PEB, compared to the dose of $68.5 \mathrm{~mJ} / \mathrm{cm}^{2}$ without PEB (Table 1). The big difference in the dose is due to the temperature difference $\left(65^{\circ} \mathrm{C}\right)$ of PEB and no-PEB: higher $\mathrm{T}$ enhances the chemical reaction of the exposed resist essentially resulting in a lower dose to achieve the target $\mathrm{CD}$ [21, 22]. For inorganic and CAR resists, the dose changes by $4-7 \mathrm{~mJ} / \mathrm{cm}^{2}$ with the change of PEB T: e.g. 6.8 and $6.5 \mathrm{~mJ} / \mathrm{cm}^{2}$ at hp $16 \mathrm{~nm}$; and 7.1 and $4.1 \mathrm{~mJ} / \mathrm{cm}^{2}$ at hp $14 \mathrm{~nm}$, respectively for lower and higher PEB T. This smaller dose difference for inorganic and CAR resist is due to the PEB temperature difference of $10^{\circ} \mathrm{C}$ (both $\mathrm{T} 3$ and $\mathrm{T} 4, \mathrm{~T} 5$ and $\mathrm{T} 6$ ). PEB does not show a strong impact on LWR for all three resists (see the last column in Table 1). 
Molecular A

(a)

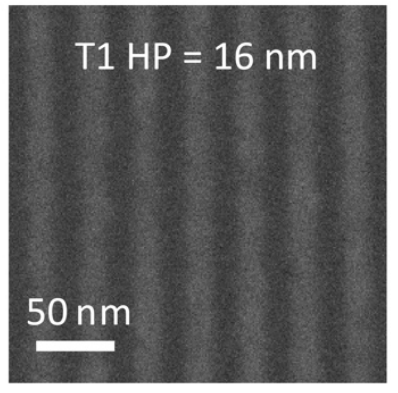

(d)

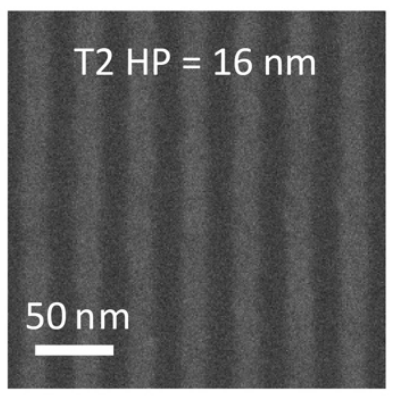

(g)

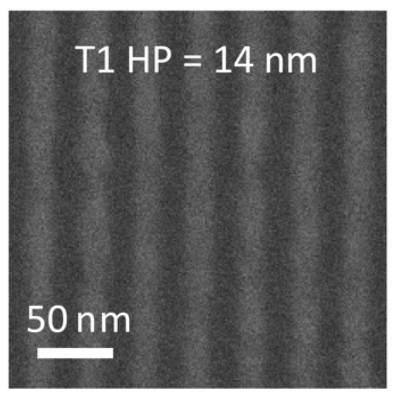

(j)

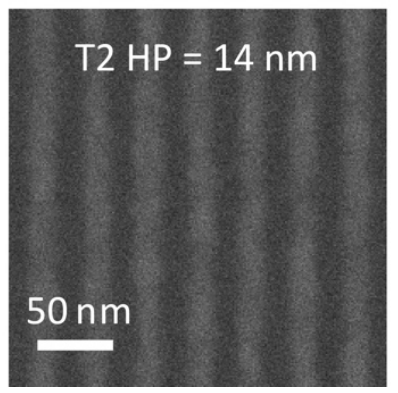

Inorganic B

(b)

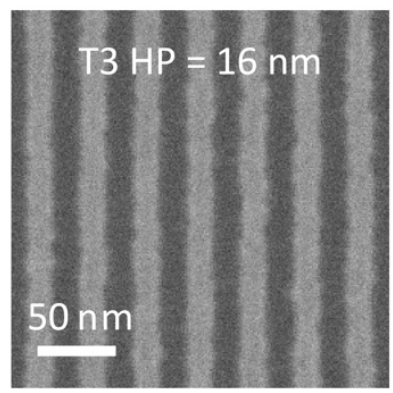

(e)

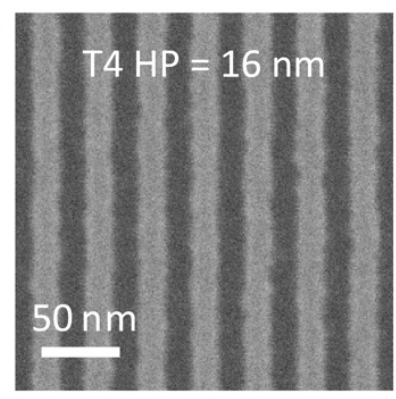

(h)

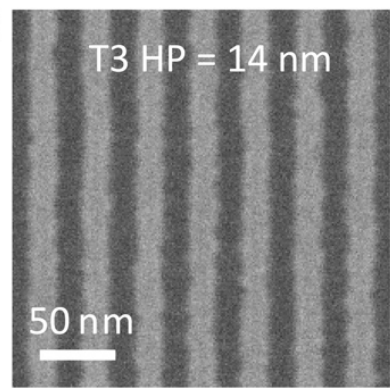

(k)

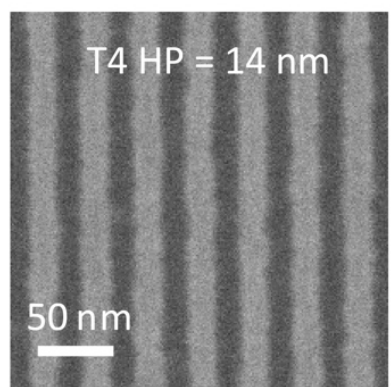

CAR C

(c)

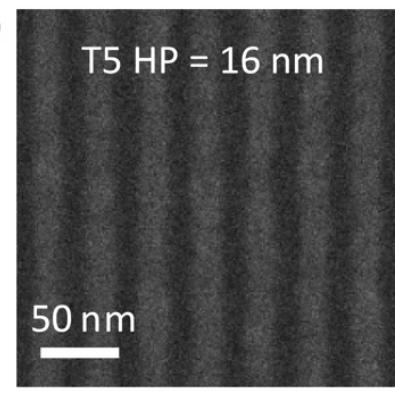

(f)

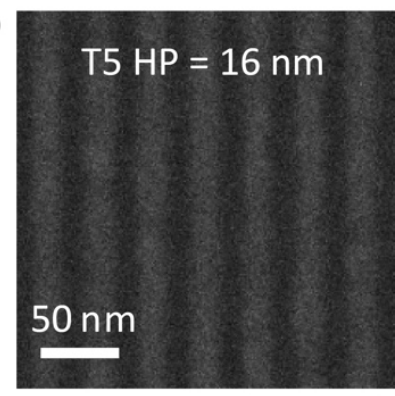

(i)

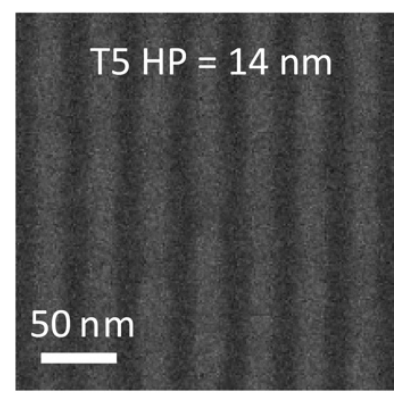

(I)

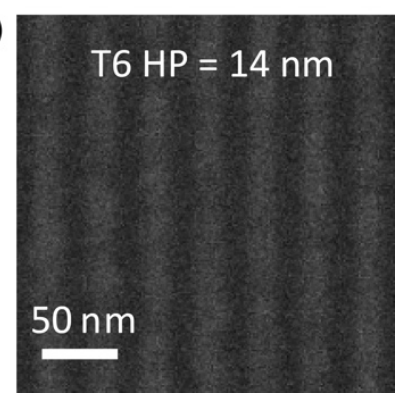

Figure 2. SEM images of line/space patterns of molecular, inorganic and CARs resists at different PEB temperatures. (a) and (d) molecular resist A, (b) and (e) Inorganic resist B and (c) and (f) CAR C for HP $16 \mathrm{~nm}$. (g) and (j) molecular resist A, (h) and (k) Inorganic resist B and (i) and (l) CAR C for HP $14 \mathrm{~nm}$. 

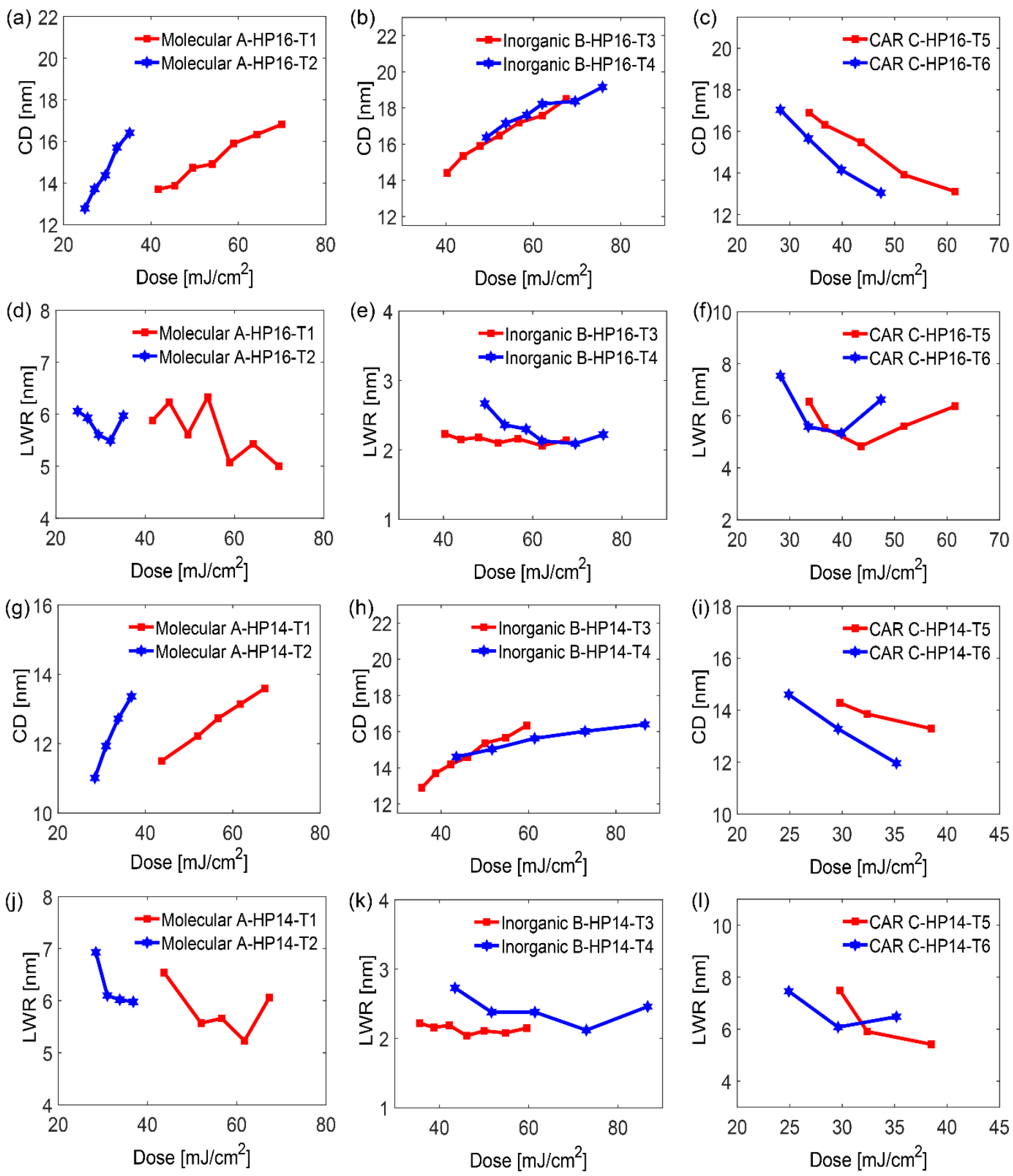

Figure 3. CD and LWR vs dose for molecular, inorganic and CAR at different PEB temperatures. (a)-(c) CD vs dose, (d)-(f) LWR vs dose for molecular, inorganic and CAR resist at HP $16 \mathrm{~nm}$ respectively. (g)-(i) CD vs dose, (j)-(l) LWR vs dose for molecular, inorganic and CAR resist at HP $14 \mathrm{~nm}$ respectively. 
Table 1. Dose to size, and LWR of the molecular A, inorganic B and CAR C resists at different temperatures for HP 16 and $14 \mathrm{~nm}$.

\begin{tabular}{|c|c|c|c|c|c|}
\hline HP (nm) & Vendor & Resist & $\begin{array}{c}\text { Temperature } \\
\left({ }^{\circ} \mathrm{C}\right)\end{array}$ & $\begin{array}{c}\text { Dose-to-size } \\
\left(\mathrm{mJ} / \mathrm{cm}^{2}\right)\end{array}$ & LWR (nm) \\
\hline \multirow{6}{*}{16} & \multirow[t]{2}{*}{ Vendor 1} & \multirow[t]{2}{*}{ Molecular A } & T1 no PEB & 62.4 & 4.9 \\
\hline & & & $\mathrm{T} 2=90$ & 34.2 & 5.3 \\
\hline & \multirow[t]{2}{*}{ Vendor 2} & \multirow[t]{2}{*}{ Inorganic B } & $\mathrm{T} 3=160$ & 52.2 & 2.5 \\
\hline & & & $\mathrm{T} 4=170$ & 45.3 & 2.6 \\
\hline & \multirow[t]{2}{*}{ Vendor 3} & \multirow[t]{2}{*}{ CAR C } & $\mathrm{T} 5=60$ & 38.7 & 7.9 \\
\hline & & & $\mathrm{T} 6=70$ & 32.1 & 7.9 \\
\hline \multirow{6}{*}{14} & \multirow[t]{2}{*}{ Vendor 1} & \multirow[t]{2}{*}{ Molecular A } & T1 no PEB & 68.4 & 5.8 \\
\hline & & & $\mathrm{T} 2=90$ & 38.3 & 5.7 \\
\hline & \multirow[t]{2}{*}{ Vendor 2} & \multirow[t]{2}{*}{ Inorganic B } & $\mathrm{T} 3=160$ & 44.5 & 2.4 \\
\hline & & & $\mathrm{T} 4=170$ & 37.4 & 2.7 \\
\hline & \multirow[t]{2}{*}{ Vendor 3} & \multirow[t]{2}{*}{ CAR C } & $\mathrm{T} 5=60$ & 31.1 & 7.5 \\
\hline & & & $\mathrm{T} 6=70$ & 26.9 & 8.3 \\
\hline
\end{tabular}

The effect of resist film thickness (FT) on the dose and LWR was also studied. Fig. 4 shows the SEM images of the hp 16 and $14 \mathrm{~nm}$ at different FTs. The comparison of dose-to-size and LWR for all three resists at different resolution and FT is listed in Table 2 and Fig. 5. The molecular and CAR resists are more sensitive to the FT: as one can see there is a clear dependency of the CD on the dose (Fig. 5 (a) and (c) for hp $16 \mathrm{~nm}$, Fig. 5 (g) and (i) for hp $14 \mathrm{~nm}$ ). No obvious difference in D2S was observed for inorganic resist (see Fig. 5 (b) and (h)). The FT has the strongest effect on the LWR for CAR (compare blue and red curve in Fig. 5(f) and (l)). To get target CD, $3 \mathrm{~nm}$ thicker resist film requires around 20\% more dose $\left(64.3 \mathrm{~mJ} / \mathrm{cm}^{2}\right.$ vs $53.9 \mathrm{~mJ} / \mathrm{cm}^{2}$ for hp $16 \mathrm{~nm}$ and $60.44 \mathrm{~mJ} / \mathrm{cm}^{2}$ vs $51.1 \mathrm{~mJ} / \mathrm{cm}^{2}$ for hp $\left.14 \mathrm{~nm}\right)$ for molecular resist D. Similarly, 20\% more dose is needed for $10 \mathrm{~nm}$ thicker film for CAR resist E $\left(14.7 \mathrm{~mJ} / \mathrm{cm}^{2}\right.$ more for $\mathrm{hp} 16 \mathrm{~nm}$ and 9.8 $\mathrm{mJ} / \mathrm{cm}^{2}$ more for hp $14 \mathrm{~nm}$ ). The FT does not show strong influence on the dose in case of inorganic resist E as $2 \mathrm{~nm}$ FT difference only change the dose by less than $4 \%$ for both hp $16 \mathrm{~nm}\left(94.7 \mathrm{~mJ} / \mathrm{cm}^{2}\right.$ vs $\left.91.4 \mathrm{~mJ} / \mathrm{cm}^{2}\right)$ and hp $14 \mathrm{~nm}(74.6$ $\mathrm{mJ} / \mathrm{cm}^{2}$ vs $71.9 \mathrm{~mJ} / \mathrm{cm}^{2}$ ). The FT shows the strongest influence on LWR for CAR resist F: $10 \mathrm{~nm}$ lower FT almost doubled the LWR for hp $16 \mathrm{~nm}$ (2.62 vs $5.62 \mathrm{~nm}$ ) and for hp $14 \mathrm{~nm}$ (3.7 vs $5.8 \mathrm{~nm}$ ). FT was found to strongly affect LWR for inorganic resist $\mathrm{E}$ (13\% and 30\% difference for hp 16 and $14 \mathrm{~nm}$, respectively). In case of molecular resist, the effect is not that significant (6.5\% and 10\% for hp 16 and $14 \mathrm{~nm}$, respectively). The FT has the strongest effect on LWR for CAR resist due to the strong dependency of the photo-acid diffusion on the FT [21, 22]. 
Molecular D

(a)

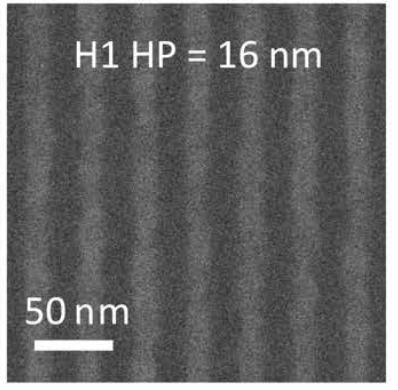

(d)

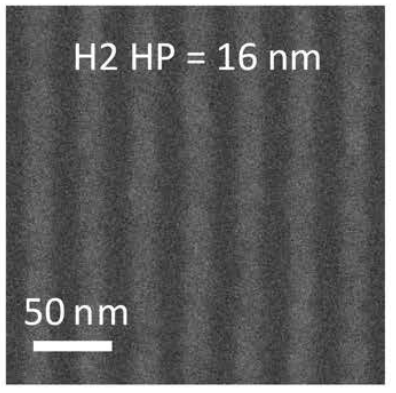

(g)

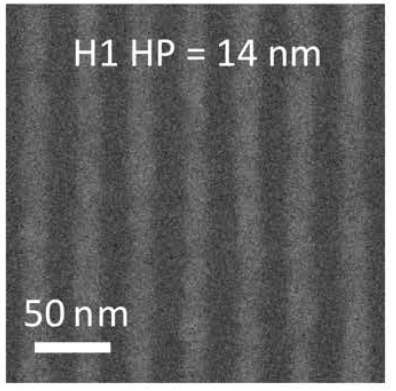

(j)

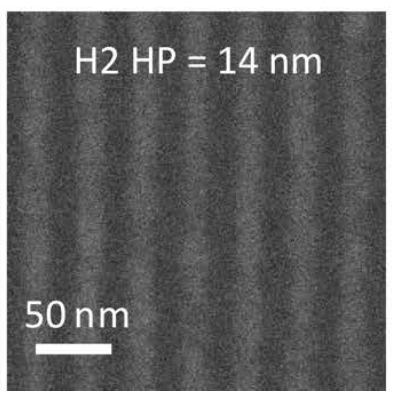

Inorganic E

(b)

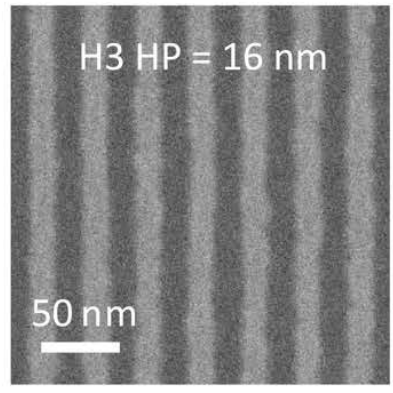

(e)

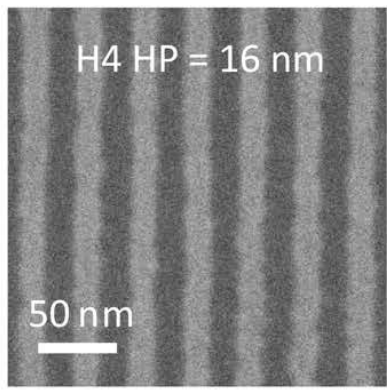

(h)

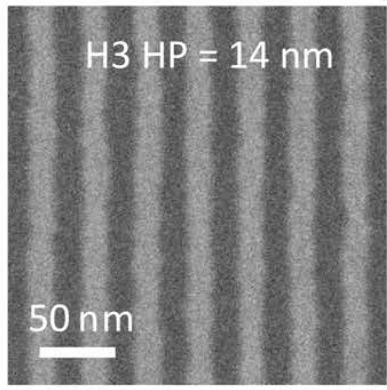

(k)

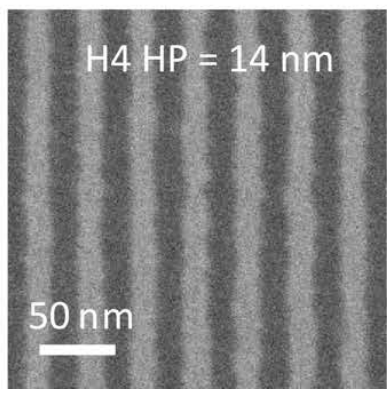

(c)

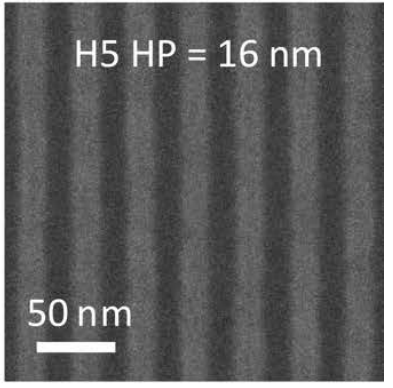

(f)

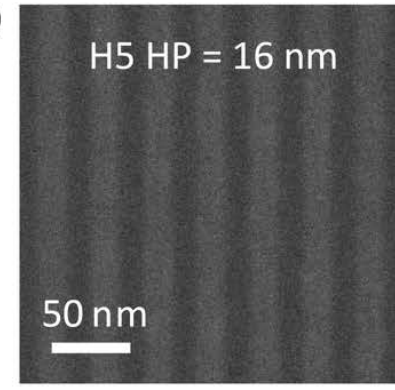

(i)

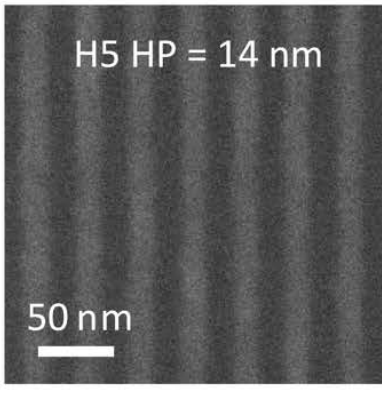

(I)

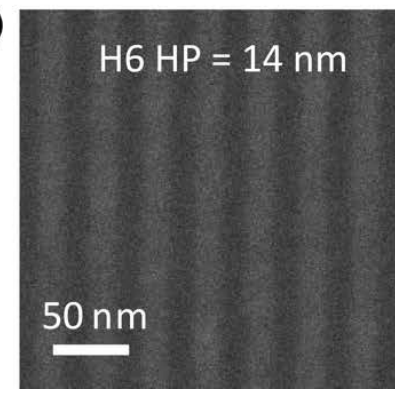

Figure 4. SEM images of line/space patterns of molecular, inorganic and CARs resists at different FT. (a) and (d) molecular resist A, (b) and (e) Inorganic resist B and (c) and (f) CAR C for HP $16 \mathrm{~nm}$. (g) and (j) molecular resist A, (h) and (k) Inorganic resist B and (i) and (l) CAR C for HP $14 \mathrm{~nm}$. 

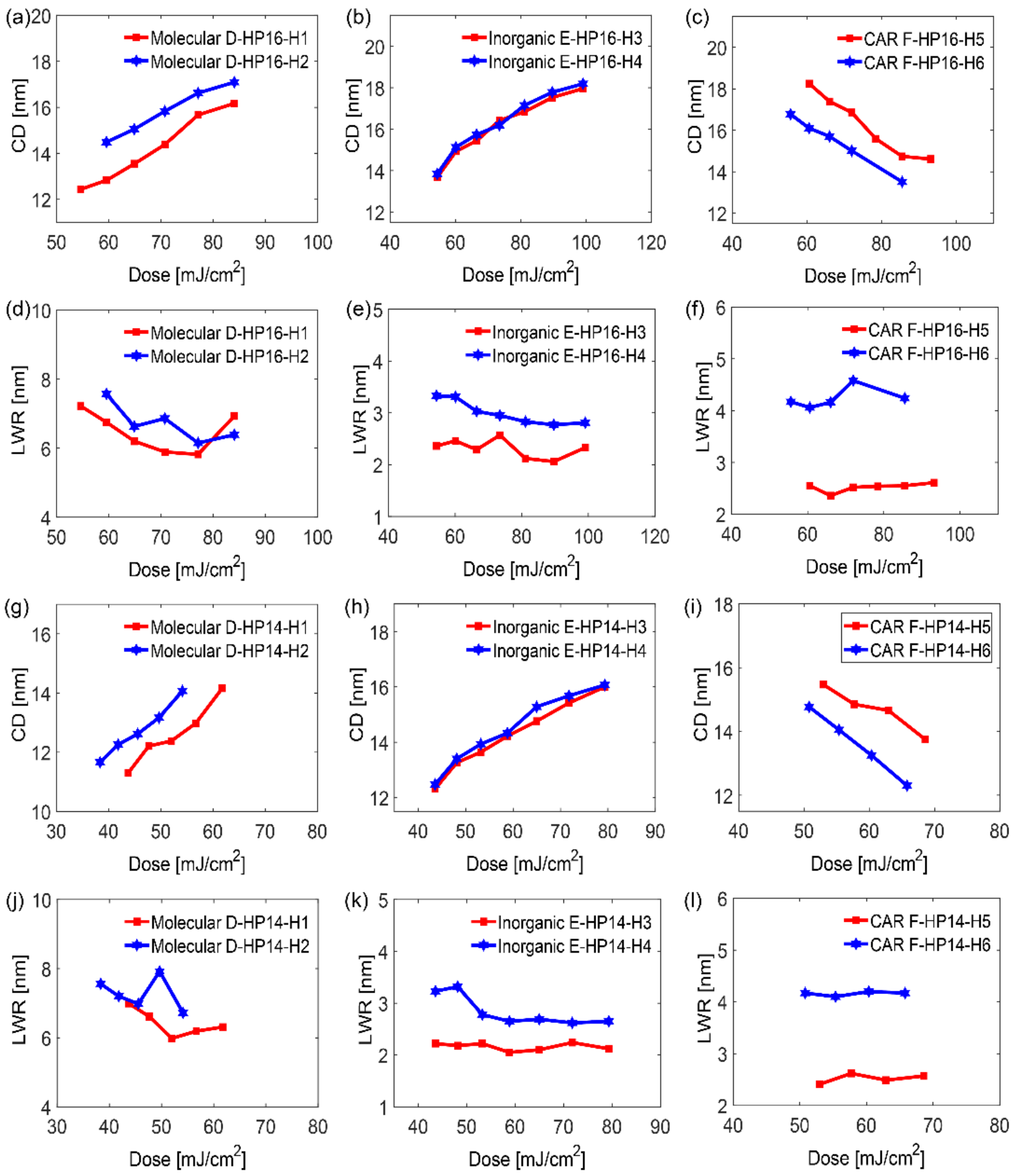

Figure 5. CD and LWR vs dose for molecular, inorganic and CAR at different film thickness (FT). (a)-(c) CD vs dose, (d)-(f) LWR vs dose for molecular, inorganic and CAR resist at HP $16 \mathrm{~nm}$ respectively. (g)-(i) CD vs dose, (j)-(l) LWR vs dose for molecular, inorganic and CAR resist at HP $14 \mathrm{~nm}$ respectively. 
Table 2. Dose to size, and LWR of the molecular A, inorganic B and CAR C resists at different FT for HP 16 and $14 \mathrm{~nm}$.

\begin{tabular}{|c|c|c|c|c|c|}
\hline HP (nm) & Vendor & Resist & $\begin{array}{c}\text { Film } \\
\text { thickness } \\
\text { (nm) }\end{array}$ & $\begin{array}{c}\text { Dose-to- } \\
\operatorname{size}\left(\mathbf{m J} / \mathrm{cm}^{2}\right)\end{array}$ & LWR (nm) \\
\hline \multirow{6}{*}{16} & \multirow[t]{2}{*}{ Vendor 1} & \multirow[t]{2}{*}{ Molecular D } & $\mathrm{H} 1=23$ & 64.2 & 5.6 \\
\hline & & & $\mathrm{H} 2=20$ & 53.9 & 5.8 \\
\hline & \multirow[t]{2}{*}{ Vendor 2} & \multirow[t]{2}{*}{ Inorganic E } & $\mathrm{H} 3=18$ & 94.7 & 3.4 \\
\hline & & & $\mathrm{H} 4=16$ & 91.3 & 3.9 \\
\hline & \multirow[t]{2}{*}{ Vendor 3} & \multirow[t]{2}{*}{ CAR F } & H5 = 29 & 76.4 & 2.6 \\
\hline & & & H6 $=19$ & 61.6 & 5.6 \\
\hline \multirow{6}{*}{14} & \multirow[t]{2}{*}{ Vendor 1} & \multirow[t]{2}{*}{ Molecular D } & $\mathrm{H} 1=23$ & 60.4 & 5.7 \\
\hline & & & $\mathrm{H} 2=20$ & 51.1 & 6.4 \\
\hline & \multirow[t]{2}{*}{ Vendor 2} & \multirow[t]{2}{*}{ Inorganic E } & $\mathrm{H} 3=18$ & 74.6 & 2.5 \\
\hline & & & $\mathrm{H} 4=16$ & 71.9 & 3.7 \\
\hline & \multirow[t]{2}{*}{ Vendor 3} & \multirow[t]{2}{*}{ CAR F } & H5 $=29$ & 65.3 & 3.7 \\
\hline & & & $\mathrm{H} 6=19$ & 55.5 & 5.7 \\
\hline
\end{tabular}

\section{CONCLUSIONS}

We presented some of the results of the EUV resist screening performed with the EUV-IL tool at PSI. The PEB affects the dose for all three types of resists, (molecular, inorganic and CAR). As expected, we observed that low PEB requires more energy to resolve the same $\mathrm{CD}$. For the molecular resist, in case of no PEB, the dose-to-size is twice as high as the dose with PEB of $90{ }^{\circ} \mathrm{C}$. Thicker resist layer requires higher dose to resolve the same CD for all resist types. However, FT has a stronger impact on LWR for CAR resist, (LWR increased by a factor of 2 with a $10 \mathrm{~nm}$ increase in FT). Based on the results of the evaluation, it can be concluded that there is still room for improvement in printing high-resolution LS patterns for high-NA EUVL with reasonable dose and LWR for molecular, inorganic and CAR resists.

\section{ACKNOWLEDGEMENTS}

The authors wish to thank Markus Kropf for his technical assistance. Part of this work was performed at the Swiss Light Source (SLS), Paul Scherrer Institute.

\section{REFERENCES}

[1] M. v. d. Brink, “Cost-effective shrink with holistic lithography, extended by EUV,” Proc. EUVL Symp., Maastricht, The Netherlands, (2015).

[2] E. Buitrago, M. Meeuwissen, O. Yildirim, R. Custers, R. Hoefnagels, G. Rispens, M. Vockenhuber, I. Mochi, R. Fallica, Z. Tasdemir, and Y. Ekinci, "State-of-the-art EUV materials and processes for the 7nm node and beyond,” Proc. SPIE, 10143, 8 (2017).

[3] C. Fouquet, "EUV Products and Business Opportunity,” ASML SMALL TALK 2018., VELDHOVEN, The Netherlands, (2018).

[4] J. Finders, "EUV lithography: update on scanner and infrastructure progress," EMLC 35th European Mask and Lithography Conference Dresden, Germany, (2019). 
[5] C. Zahlten, P. Gräupner, J. v. Schoot, P. Kürz, J. Stoeldraijer, B. Kneer, and W. Kaiser, "High-NA EUV lithography: pushing the limits,” Proc. SPIE, 111770B, (2019).

[6] J. v. Schoot, E. v. Setten, K. Troost, F. Bornebroek, R. v. Ballegoij, S. Lok, J. Stoeldraijer, J. Finders, P. Graeupner, J. Zimmermann, P. Kuerz, M. Pieters, and W. Kaiser, "High-NA EUV lithography exposure tool progress,” Proc. SPIE, 1095707, (2019).

[7] T. Wallow, C. Higgins, R. Brainard, K. Petrillo, W. Montgomery, C.-S. Koay, G. Denbeaux, O. Wood, and Y. Wei, "Evaluation of EUV resist materials for use at the $32 \mathrm{~nm}$ half-pitch node," Proc. SPIE, 6921F (2008).

[8] E. Buitrago, R. Fallica, D. Fan, T. S. Kulmala, M. Vockenhuber, and Y. Ekinci, "SnOx high-efficiency EUV interference lithography gratings towards the ultimate resolution in photolithography,” Microelectronic Engineering, 155, 44-49 (2016).

[9] Y. Ekinci, M. Vockenhuber, B. Terhalle, M. Hojeij, L. Wang, and T. R. Younkin, "Evaluation of resist performance with EUV interference lithography for sub-22-nm patterning,” Proc. SPIE, 8322, 11 (2012).

[10] N. Mojarad, D. Fan, J. Gobrecht, and Y. Ekinci, "Broadband interference lithography at extreme ultraviolet and soft X-ray wavelengths,” Optics Letters, 39(8), 2286-2289 (2014).

[11] N. Mojarad, J. Gobrecht, and Y. Ekinci, "Interference lithography at EUV and soft X-ray wavelengths: Principles, methods, and applications,” Microelectronic Engineering, 143, 55-63 (2015).

[12] A. M. Goethals, R. Gronheid, F. Van Roey, H. H. Solak, and Y. Ekinci, "Progress in EUV Resist Performance,” Journal of Photopolymer Science and Technology, 19(4), 501-506 (2006).

[13] E. Buitrago, S. Nagahara, O. Yildirim, H. Nakagawa, S. Tagawa, M. Meeuwissen, T. Nagai, T. Naruoka, C. Verspaget, R. Hoefnagels, G. Rispens, G. Shiraishi, Y. Terashita, Y. Minekawa, K. Yoshihara, A. Oshima, M. Vockenhuber, and Y. Ekinci, "Sensitivity enhancement of chemically amplified resists and performance study using extreme ultraviolet interference lithography,” Proc. SPIE, 15, 9 (2016).

[14] Z. Tasdemir, X. Wang, I. Mochi, L. v. Lent-Protasova, M. Meeuwissen, R. Custers, G. Rispens, R. Hoefnagels, and Y. Ekinci, "Evaluation of EUV resists for 5nm technology node and beyond," Proc. SPIE,108090L (2018).

[15] X. Wang, Z. Tasdemir, I. Mochi, M. Vockenhuber, L. v. Lent-Protasova, M. Meeuwissen, R. Custers, G. Rispens, R. Hoefnagels, and Y. Ekinci, "Progress in EUV resists towards high-NA EUV lithography,” Proc. SPIE,109570A (2019).

[16] N. Mojarad, M. Hojeij, L. Wang, J. Gobrecht, and Y. Ekinci, “Single-digit-resolution nanopatterning with extreme ultraviolet light for the 2.5 nm technology node and beyond,” Nanoscale, 7(9), 4031-4037 (2015).

[17] D. Fan, and Y. Ekinci, "Photolithography reaches $6 \mathrm{~nm}$ half-pitch using EUV light,” Proc. SPIE, 9776,11 (2016).

[18] X. Wang, L.-T. Tseng, D. Kazazis, Z. Tasdemir, M. Vockenhuber, I. Mochi, and Y. Ekinci, "Studying resist performance for contact holes printing using EUV interference lithography,” Journal of Micro/Nanolithography, MEMS, and MOEMS, 18(1), 1-11, 11 (2019).

[19] L. Wang, H. H. Solak, and Y. Ekinci, "Fabrication of high-resolution large-area patterns using EUV interference lithography in a scan-exposure mode,” Nanotechnology, 23(30), 305303 (2012).

[20] G. F. Lorusso, T. Sutani, V. Rutigliani, F. v. Roey, A. Moussa, A.-L. Charley, C. Mack, P. Naulleau, V. Constantoudis, M. Ikota, T. Ishimoto, and S. Koshihara, “The need for LWR metrology standardization: the imec roughness protocol,” Proc. SPIE,105850D (2018).

[21] R. Gronheid, F. V. Roey, and D. V. Steenwinckel, "Using KLUP for Understanding Trends in EUV Resist Performance,” Journal of Photopolymer Science and Technology, 21(3), 429-434 (2008).

[22] A. Robinson, and R. Lawson, "Materials and Processes for Next Generation Lithography,” Amsterdam, Netherlands: Elsevier, (2016). 